\title{
Naissance et petite enfance d'un garçon en Kabylie (Témoignage)
}

Taos Amrouche

\section{OpenEdition}

1 Journals

Édition électronique

URL : https://journals.openedition.org/encyclopedieberbere/2670

DOI : 10.4000/encyclopedieberbere.2670

ISSN : 2262-7197

Éditeur

Peeters Publishers

Édition imprimée

Date de publication : 4 octobre 2012

Pagination : $5227-5230$

ISBN : 978-90-429-2640-0

ISSN : 1015-7344

\section{Référence électronique}

Taos Amrouche, « Naissance et petite enfance d'un garçon en Kabylie (Témoignage) », Encyclopédie berbère [En ligne], 33 | 2012, document N08, mis en ligne le 22 novembre 2020, consulté le 17 février 2022. URL : http://journals.openedition.org/encyclopedieberbere/2670 ; DOI : https://doi.org/10.4000/ encyclopedieberbere. 2670

Ce document a été généré automatiquement le 17 février 2022.

(c) Tous droits réservés 


\title{
Naissance et petite enfance d'un garçon en Kabylie (Témoignage)
}

\author{
Taos Amrouche
}

1 [Texte d'une émission de Taos Amrouche. Poste de Tunis PTT, audition du mardi 19 septembre 1939, 16h 40. Reproduit avec l'aimable autorisation de sa fille, Laurence Bourdil-Amrouche.]

2 La naissance d'un garçon est saluée hautement, et sa petite enfance donne lieu à toutes sortes de réjouissances. Par contre, l'accueil que l'on réserve à une fille est assez froid : on ne fait pas parler la poudre, on ne lance pas à pleine voix l'appel à la joie prolongé de joyeux youyou.

3 Certes, on prend soin de l'accouchée mais elle-même sait qu'elle n'a pas droit à des félicitations très chaleureuses. On accepte la naissance d'une fille comme l'on accepte l'inévitable, mais il ne convient pas de s'en réjouir. Les parents, les amis qui viennent voir l'accouchée lui disent: «Bien-venue soit la dot» au lieu de «Bien-venue soit l'enfant » comme s'ils voulaient consoler en lui rappelant que plus tard le mariage de sa fille lui rapportera une bonne somme. Aussi n'est-il pas de femme qui ne rêve de donner le jour à un garçon, de recevoir cette faveur du ciel.

4 Jusqu'au jour de la délivrance, elle travaille durement: en prévision du temps où elle sera étendue, sans forces, où elle sera une convalescente, telle une fourmi elle amasse des provisions. Elle se hâte d'achever la couverture de laine ou le burnous qui est sur le métier. Elle moud chaque jour plus de blé qu'elle n'en consomme et elle emplit ainsi peu à peu un sac de farine. Elle fait une réserve d'huile, d'épices, de poivre rouge : spécialité du pays qui est à la base de l'alimentation en Kabylie. Elle recommande plusieurs mois à l'avance à toutes les femmes qui élèvent des poules de lui réserver des œufs et des poulets; elle leur verse des arrhes au besoin.

5 Le jour tant attendu est arrivé : un garçon est né ; le cycle des réjouissances est ouvert. La famille de l'accouchée se trouve-t-elle dans un village voisin ou dans une contrée éloignée? Rien ne l'empêchera d'accourir avec des présents. Il est en effet de la plus haute importance que l'accouchée soit assistée par les siens et gâtée par eux, qu'on ne la sente pas abandonnée et comme orpheline. Si sa mère, son père, sa grand-mère, ses 
frères sont auprès d'elle; s'ils arrivent de loin les mains pleines d'offrandes pour s'unir à sa joie, l'accouchée en recueillera du prestige. Son mari aura plus d'égards pour elle, sa belle famille aussi. Devant ce rempart protecteur qui l'entoure toutes celles qui la jalousent, qui lui en veulent et chercheraient à lui nuire sont désarmées. C'est pourquoi les parents de l'accouchée ne manquent pas de venir. Et ils s'endetteraient plutôt que de venir les mains vides! N'auraient-ils qu'une pioche, comme dit un proverbe kabyle, ils la vendraient pour faire face à cette obligation car pour eux c'est une question de nnif*, c'est à dire d'honneur. Je ne saurais trop insister sur ce point. Non seulement la présence des parents auprès de l'accouchée est indispensable, mais encore cette présence doit s'accompagner de dons. Plus le dérangement aura été grand et les dons nombreux, plus l'accouchée se sentira honorée et fière. La mère ne peut-elle venir ? La grand-mère, un frère, un oncle la remplacent.

L'admirable, le majestueux « appel à la joie » est lancé par les femmes du voisinage qui avancent de rue en rue en le chantant, les paumes des mains ouvertes et tendues. Ces femmes sont âgées pour la plupart et bien vêtues.

\begin{tabular}{|l|l|}
\hline Ô toi, de qui j'ai partagé la joie, & A win umi ferhę \\
\hline Viens et réjouis-toi avec moi, & yas-ed yerr-iyi \\
\hline Rends-moi la joie que je t'ai donnée! & yas-ed yerr-iyi \\
\hline Depuis longtemps, depuis si longtemps & xirellah ayagi \\
\hline Nous étions sur le versant d'ombre! & degg umalu ay nella \\
\hline Mais voici que l'astre vient de naître, & ilul-ed waggur \\
\hline Déjà se répand sa lumière, & tcerq-ed tziri \\
\hline La lumière de la pleine lune! & tcerq-ed tziri \\
\hline
\end{tabular}

7 Dans la maison visitée par la joie, une grande animation règne: des coups de feu retentissent dans la cour, d'autres leur répondent. Les hommes doivent faire parler la poudre et annoncer ainsi qu'un garçon a vu le jour. Des chants d'allégresse, des youyou éclatent de tous côtés, emplissent la maison et les rues.

8 La jeune accouchée est étendue au fond de la pièce. On lui présente le gâteau épais et nourrissant fait de farine, d'œufs et de beurre et enduit de miel que toute accouchée doit manger chaque matin et à l'heure du goûter, durant quarante jours. Et puis, les visiteurs et les offrandes affluent: un agneau sur pied orné sur le front et sur le dos d'un dessin au henné, des corbeilles d'œufs, du miel, du beurre, du blé, des vêtements neufs - foulards aux teintes vives, aux belles franges, gandouras de soie accompagnent les parents de l'accouchée. A défaut d'agneau sur pied, un quartier de mouton, une importante quantité de viande car plusieurs repas devront être offerts et l'accouchée doit manger force grillades pour retrouver des forces. Les amies nombreuses et toutes endimanchées apportent des œufs, de la semoule, des figues sèches, des fruits. 
9 Le premier jour plusieurs poulets sont tués et un couscous léger est préparé : l'accouchée est servie la première. Dans l'après-midi accourent de tous les villages voisins les parentes éloignées. Elles viennent pour se réjouir et danser. Des jeunes filles rieuses dans leurs plus beaux atours et des enfants les accompagnent. La maison de l'accouchée est envahie. La sauterie s'organise : des mains impatientes se saisissent des tambourins, des bidons donnent le rythme. Alors les pieds agiles esquissent des pas légers, les têtes gracieuses s'inclinent, les épaules frémissent, les bras agitent les foulards qui dessinent dans l'air toutes sortes d'arabesques. Les vieilles femmes aussi se jettent dans la danse et d'une voix chevrotante ou cassée lancent leur chanson. Ils arrivent quelquefois que les iferrahen, la troupe d'aèdes berbères qui prend part à toutes les réjouissances, soient de passage dans le village. Elle entre et l'enthousiasme monte (les danses deviennent plus folles). L'orchestre rudimentaire s'enrichit d'une ghaïta et d'un bon tambourin. Aux intermèdes, on distribue aux enfants des œufs durs, des friandises.

10 Le troisième jour, l'enfant est mis dans son berceau. Qu'il est charmant, ce berceau ! Il ressemble à une coupe ; il est fait de tiges de laurier rose et d'alfa. Deux grandes et flexibles tiges s'entrecroisent au-dessus de lui et viennent s'attacher à la coupe en dessinant deux anses. C'est de là que l'on suspendra le berceau à une poutre. C'est dans ce nid que l'enfant est déposé, Ce nid suspendu que la plus faible poussée fait osciller, se balancer... Ce jour-là, une coutume exige que l'on fasse en bonne quantité des crêpes saupoudrées de sucre non raffiné et que l'on en distribue aux connaissances, aux amis.

11 Puis, arrive le septième jour ! L'agneau est sacrifié, un important repas est offert : il s'agit de nourrir une quarantaine de personnes. Dès le matin, plusieurs femmes roulent le grain. D'autres coupent les oignons en gros morceaux, les teintent de poivre rouge, et épluchent les légumes. Un homme découpe la viande en portions. Dans la cour plusieurs feux de bois sont allumés et plusieurs marmites fument. Avant la tombée de la nuit, les convives arrivent. Ils sont reçus dans le grand vestibule ou bien dans une vaste pièce dont le sol est tendu de nattes, de tapis, de couvertures. Le couscous est servi dans de larges plats en bois à pied. De vieilles femmes distribuent des cuillers en bois, des récipients pleins d'eau et assurent le service.

Peu à peu tout rentre dans l'ordre. Le temps de convalescence s'achève. L'enfant n'est montré qu'à bon escient, car le mauvais œil est à craindre. Trois, quatre mois passent, l'enfant pousse sa première dent! C'est un miracle qui doit être salué : la nouvelle est criée, chantée! Les visiteuses emplissent à nouveau la maison. C'est encore une occasion de chanter et de danser. On entoure l'enfant, on verse au-dessus de sa tête une petite poignée de blé pour que ses dents poussent aussi jolies, aussi menues que des grains de blé. On distribue des cacahuètes, des dattes, des noix, des figues sèches, des raisins secs aux enfants.

Un peu plus tard, l'enfant peut se tenir assis! Le voisinage en est informé et tout le village. Des jeunes filles viennent féliciter la mère et voir l'enfant. Elles accourent, heureuses de revêtir leurs plus beaux habits, de délaisser leur ouvrage pour chanter et danser. L'enfant est assis sur des coussins, une belle couverture rouge l'entoure comme un rempart et l'empêche de tomber. Encore des chants, des éclats de rire, des danses!

Enfin, quelques années après, c'est la circoncision! La mère, ce jour-là, met son abzim au-dessus de son foulard, en guise de couronne, et son khalkhal, le haut bijou d'argent qui orne et emprisonne sa cheville les jours de fêtes. Les iḍebbalen, ceux qui jouent du tambour, sont commandés. L'appel à la joie, suivi de youyou, retentit. La poudre parle. 
Un agneau est sacrifié, un grand repas offert comme pour une noce. Les invités affluent. L'après-midi, un bal est donné dans la cour. Les chants coulent de toutes les lèvres: tambourins, ghaïtas, tambours font un joyeux vacarme. Les foulards se déploient, les danses succèdent aux danses. C'est la dernière réjouissance avant les fiançailles d'un garçon, aussi a-t-elle une importance et un éclat tout particuliers.

INDEX

Mots-clés : Ethnologie, Kabylie, Rite 